\title{
PENENTUAN PRIORITAS LOKASI BUDIDAYA RUMPUT LAUT DI KABUPATEN SAMPANG MENGGUNAKAN METODE TOPSIS
}

\author{
Bakir $^{1}$, Hozairi ${ }^{2}$ \\ ${ }^{1}$ Program Studi Sistem Informasi, Universits Islam Madura, Pamekasan, Indonesia \\ ${ }^{2}$ Program Studi Teknik Informatika, Universits Islam Madura, Pamekasan, Indonesia \\ bakir.madura@gmail.com,dr.hozairi@gmail.com
}

\begin{abstract}
ABSTRAK
Keberhasilan didalam budidaya rumput laut ditentukan oleh kondisi lahan rumput laut dan pemilihan lokasi lahan yang sesuai dengan kriteria tersebut merupakan salah satu penentu dalam keberhasilan budidaya. Dalam pemilihan lokasi lahan rumput laut yang baik tentunya harus memperhatikan yang menjadi faktor penentu termasuk biofisik yang dibutuhkan dalam budidaya rumput laut dan hal ini menjadi sangat penting sebagai bahan dasar informasi pengetahuan agar memperoleh hasil yang baik dan tidak menghambat dalam proses budidaya dan dapat mempengaruhi kualitas hasil produksi, kemudian perlu adanya evaluasi terhadap hasil budidaya rumput laut diantaranya aspek kesesuaian dan pemanfaatan lahan, serta aspek ekonomis dan operasional. Penentuan lokasi lahan rumput laut merupakan permasalahan multiobyektif sehingga memerlukan metode yang mampu menyelesaiakn permasalahan komplek tersebut. Metode TOPSIS merupakan sebuah metode perangkingan dimana alternatif dirangking berdasarkan bobot masing-masing alternative. TOPSIS memiliki konsep dimana alternatif yang terpilih merupakan alternatif terbaik yang memiliki jarak terpendek dari solusi ideal positif dan jarak terjauh dari solusi ideal negatif. Penelitian ini telah merekomendasikan lokasi terbaik untuk budidaya rumput laut dengan nilai prioritas diatas $20 \%$ dari bobot keseluruhan yaitu wilayah sampang dan camplong
\end{abstract}

Keyword : rumput laut, TOPSIS, sampang

\section{PENDAHULUAN}

Pemanfaatan dan pengembangan potensi sumberdaya perairan pantai dan laut menjadi para digma baru pembangunan di masa sekarang yang harus dilaksanakan secara rasional dan berkelanjutan. Pengembangan harus realistis yang didasari oleh faktor potensi sumberdaya alam yang sangat besar. Dalam pengembangan diwilayah pantai pesisir salah satunya adalah kegiatan ekonomi pro rakyat yang digalakkan Pemerintah dengan pengembangan sumber daya alam seperti pengembangan budidaya rumput laut dengan ini diharapkan dapat merangsang pertumbuhan ekonomi rakyat akibat pengembangan dan pemanfaatan potensi lahan setempat (Siswanto \& Nugraha, 2016).

Pengembangan budidaya rumput laut di Indonesia dirintis sejak pada tahun 80-an dengan upaya merubah kebiasaan rakyat pesisir pantai ke arah budidaya rumput laut yang ramah lingkungan usaha ini dapat meningkatkan ekonomi rakyat sekitar terhadap pembudidayaan rumput laut dan untuk kelestarian lingkungan perairan pantai (Muhammad Z.Zain, 2012).

Pengembangan budidaya dan pemilihan prioritas lahan rumput laut menjadi salah satu alternatif pemberdayaan penduduk pantai pesisir yang mempunyai dan pemanfaatan potensi alam diantaranya (Paena, 2013):

1. Masyarakat pengahsilan ekonomi yang beragam.

2. Tersedianya lahan baru untuk budidaya rumput laut.

3. Teknologi budidaya yang diperlukan semakin mudah didapatkan
Keberhasilan dalam membudidayakan rumput laut ditentukan oleh beberapa kriteria yaitu: [1] wilayah/daerah yang stabil, [2] kedalaman air, [3] suhu, [4] intensitas matahari, [5] salinitas air dan [5] tanaman alga. Untuk memperoleh wilayah yang tepat maka perlu adanya suatu evaluasi dan pemilihan prioritas terbaik terhadap lahan yang akan dikelola untuk membudidayakan rumput laut. Untuk menyelesaikan permasalahan tersebut maka perlu sebuah metode yang tepat untuk menyelesaikanya, metode TOPSIS (Technique for Order Preference by Similarity to Ideal Solution) merupakan metode perangkingan dimana alternatif dirangking berdasarkan bobot masing-masing alternatif (Murnawan \& Siddiq, 2012), (Shukla, Garg, \& Agarwal, 2014).

Metode TOPSIS merupakan metode yang sering digunakan untuk mengambil keputusan, TOPSIS hampir sama dengan metode AHP dengan menggunakan kriteria sebagai indentifikator untuk menyelesaikan permasalahan multi kriteria. Metode TOPSIS memiliki banyak lebihan antara lain: (a) konsepnya sederhana dan mudah dipahami, (b) komputasinya efisien, (c) bisa dijadikan pengukur kriteria dan alternatif dan (d)prosesnya lebih cepat (Heru Lumaksono, 2017), (Hozairi, 2018).

\section{TINJAUAN PUSTAKA}

2.1. Penentuan Lokasi

Lokasi adalah letak dan tempat atau penempatan suatu benda serta keadaan pada permukaan bumi yang ada. Lokasi merupakan tempat dimana orang-orang biasa berkunjung dan bisa ditempati untuk melakukan suatu kegiatan. 
Didalam penentuan lokasi harus menjadi pertimbangan keuntungan dan kerugian dalam sesuatu pengelolaan suatu usaha, karena dalam penentuan lokasi ini juga akan mempengaruhi akan keberhasilan suatu kegiatan yang memang untuk bertujuan kegiatan usaha.

Kondisi lokasi sangat menentukan keberhasilan budidaya rumput laut. Pemilihan lokasi yang tepat akan berdampak pada pertumbuhan rumput laut yang baik. Beberapa faktor fisika-kimia yang harus menjadi perhatian didalam budidaya rumput laut diantaranya Gelombang, Arus, Salinitas, Suhu, Nitrat, Fosfat, Derajat Keasaman, Kedalaman, Kecerahan, Pasang Surut dan Oksigen Terlarut

\subsection{TOPSIS.}

TOPSIS (Technique For Orders Reference by Similarity to Ideal Solution) merupakan salah satu metode yang dapat membantu dalam pengambilan keputusan melalui kriteria dan alternatif yang harus dipilih serta melalui jarak terdekat dari solusi ideal yang positif dan jarak terjauh dari solusi ideal yang negatif. Pilihan tersebut akan diurutkan berdasarkan alternatif terpendek dan solusi ideal yang paling positif serta terbaik (Kutlu, 2012). Dengan kata lain, alternatif yang memiliki nilai yang lebih besar itulah yang lebih baik untuk dipilih.

Langkah-langkah prosedur TOPSIS dengan tahap sebagai berikut:

a. Menentukan normalisasi matriks keputusan. Nilai ternormalisasi rij dihitung dengan

$$
\begin{aligned}
& r_{i j}=\frac{x_{i j}}{\sqrt{\sum_{i=1}^{m} x_{i j}{ }^{2}}} \text { dengan } \mathrm{i}=1,2, \ldots, \mathrm{m} ; \text { dan } \mathrm{j}=1, \\
& 2, \ldots, \mathrm{n} \text {. }
\end{aligned}
$$

b. Menentukan bobot ternormalisasi matriks keputusan. Nilai bobot ternormalisasi vij dihitung dengan persamaan: $v_{i j}=w_{j} r_{i j} ; \mathrm{i}=1,2$, ..., m; dan $\mathrm{j}=1,2, \ldots, \mathrm{n}$. dimana $w_{j}$ adalah bobot dari atribut atau kriteria ke-j.

c. Menentukan solusi ideal positif dan ideal negatif. $\mathrm{A}^{+}$dan $\mathrm{A}^{-}$didefinisikan sebagai bobot ternormalisasi.

$\mathrm{A}^{+}=\left\{\mathrm{v}_{1}^{+}, \ldots, \mathrm{v}_{\mathrm{j}}^{+}, \ldots \ldots, \mathrm{v}_{\mathrm{n}}^{+}\right\}=\left\{\left(\max \mathrm{v}_{\mathrm{ij}} \mid \mathrm{f} \in\right.\right.$ $\left.\left.\mathrm{J}_{1}\right),\left(\max \mathrm{v}_{\mathrm{ij}} \mid \mathrm{f} \in \mathrm{J}_{2}\right)\right\} \mathrm{i}=1,2, \ldots \ldots, \mathrm{m}$

$\mathrm{A}^{-}=\left\{\mathrm{v}_{1}^{-}, \ldots, \mathrm{v}_{\mathrm{j}}^{-}, \ldots \ldots, \mathrm{v}_{\mathrm{n}}^{-}\right\}=\left\{\left(\min _{\mathrm{ij}} \mid \mathrm{f} \in \mathrm{J}_{1}\right)\right.$, $\left.\left(\min \mathrm{v}_{\mathrm{ij}} \mid \mathrm{f \in} \mathrm{J}_{2}\right)\right\} \quad \mathrm{i}=1,2, \ldots ., \mathrm{m}$

Dimana $\mathrm{J}_{1}$ terasosiasi dengan kriteria keuntungan dan $\mathbf{J}_{2}$ terasosiasi dengan kriteria biaya.

d. Menghitung jarak dengan menggunakan jarak Euclidean dimensi $n$. Jarak antara setiap alternatif mendapatkan solusi ideal yang positif sebagai:

$S_{i}^{+}=\sqrt{\sum_{j=1}^{n}\left(v_{i j}-v_{j}^{+}\right)^{2}} ; \mathrm{i}=1,2, \ldots, \mathrm{m}$

Hal yang sama, untuk solusi ideal negatif, diberikan sebagai:

$$
S_{i}^{-}=\sqrt{\sum_{j=1}^{n}\left(v_{i j}-v_{j}^{-}\right)^{2}} ; \mathrm{i}=1,2, \ldots, \mathrm{m}
$$

e. Hitung kedekatan relatif dengan solusi ideal. Kedekatan relatif dari alternatif $\mathrm{A}_{\mathrm{j}}$ didefinisikan sebagai:

$$
C_{i}=\frac{s_{i}^{-}}{S_{i}{ }^{+}+S_{i}}=; \mathrm{i}=1,2, \ldots, \mathrm{m}
$$

Catatan bahwa $0 \leq \mathrm{C}_{\mathrm{i}} \leq 1$, dimana $\mathrm{C}_{\mathrm{i}}=0$ bila $\mathrm{A}_{\mathrm{i}}$ $=\mathrm{A}^{-}$, dan $\mathrm{C}_{\mathrm{i}}=1$ bila $\mathrm{A}_{\mathrm{i}}=\mathrm{A}^{+}$

f. Melakukan perankingan pilihan alternatif. Memilih sebuah alternatif $\mathrm{C}_{\mathrm{i}}$ dengan nilai maksimum atau meranking alternatif terbaik $\mathrm{C}_{\mathrm{i}}$ secaradescending.

\subsection{Rumput Laut.}

Rumput laut adalah ganggang yang bisa hidup di dalam laut dan tergolong dalam divisio thallophyta. Keseluruhan dari tanaman ini merupakan batang yang dikenal sebagai sebutan thallus, bentuk thallus rumput laut bermacammacam diantaranya bulat seperti tabung, pipih, dan gepeng, bulat seperti kantong, rambut dll. Thallus ini tersusun oleh satu sel (uniseluler) atau banyak sel (multiseluler).

Sedangkan percabangan thallus ada yang thallus dichotomus (dua dua terus menerus), pinate (dua-dua berlawanan sepanjang thallus utama), pectinate (berderet searah pada satu sisi thallus utama) dan ada juga yang sederhana tidak bercabang. Sifat substansi thallus ini juga beraneka ragam ada yang lunak seperti gelatin (gelatinous), keras diliputi atau mengandung zat kapur (calcareous\}, dan lunak bagaikan tulang rawan (cartilagenous), berserabut (spongeous) dan sebagainya. (Soegiarto et al, 1978).

\section{METODE PENELITIAN}

\subsection{Pengumpulan Data}

Adapun metode dalam pengumpulan data yang digunakan adalah dengan menggunakan :

a) Data Primer

Data primer adalah data yang diambil secara langsung dari sumber.Data ini adalah lokasi lahan rumput laut yang ada di kabupaten Sampang.

b) Data Sekunder.

Data sekunder adalah data yang diperoleh secara tidak langsung.Data ini dapat diperoleh dari buku, jurnal dan internet. Data sekunder dalam tugas akhir ini adalah:

- Data kriteria tambak rumput laut

- Data rumput laut.

\section{c) Penentuan Kriteria}

Lokasi yang akan dinilai merupakan lokasi yang berada di kabupaten Samapng. Lokasi ini kemudian dinilai untuk masing-masing kriteria. Nilai ini akan diproses dengan menggunakan metode TOPSIS

\subsection{Perancangan Sistem}

Pada perancangan user interface ini dilakukan dilakukan perancangan sistem aliran data sistem diawali dari admin yang memasukkan data kriteria. 
Data kriteria hanya dapat dimasukkan oleh admin karena data kriteria tidak akan mengalami perubahan. Sedangkan user bertugas untuk memasukkan data lokasi yang akan dinilai. Data kriteria dan data lokasi akan dimasukkan ke dalam sistem. Hasil pengolahan sistem akan menghasilkan nilai untuk tiap lokasi yang dinilai. Hasil penilaian ini akan diterima kembali oleh user sebagai pihak yang melakukan proses penilaian.

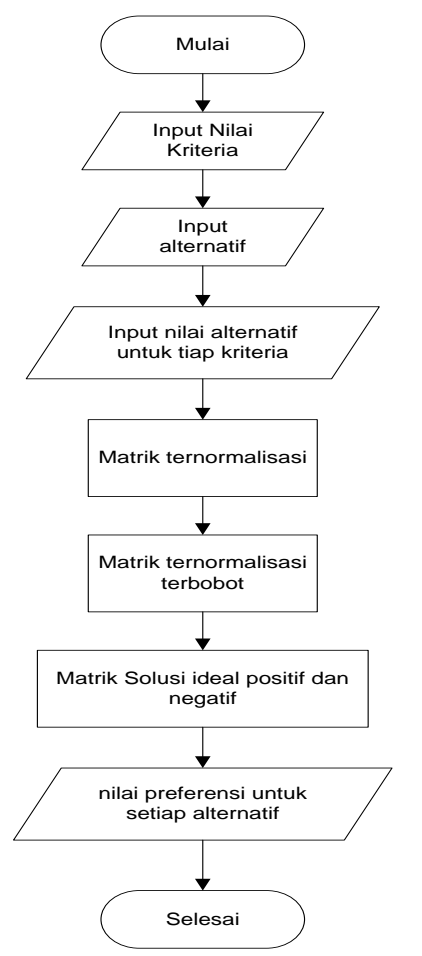

Gambar 1. Diagram Alir TOPSIS

Berdasarkan Gambar 1, ketika user akan melakukan penilaian menggunakan metode TOPSIS, user bisa memasukkan data kriteria dan data alternatif. Data alternatif merupakan data lokasi yang akan dinilai. Selanjutnya pengguna memberikan nilai untuk alternatif pada masingmasing kriteria. Selanjutnya dari nilai yang ada akan dibuat matrik ternormalisasi. Matrik yang sudah ada kemudian dinormalisasi lagi sehingga menjadi matrik ternormalisasi terbobot.

Gambar 2 menjelaskan bahwa sistem terdiri dari beberapa menu yaitu menu Home yang akan menampilkan informasi tentang sistem, menu Input Data yang menampilkan informasi tentang proses input data. Input data ini akan memasukkan data kriteria yang digunakan dalam proses penilaian dan data lokasi yang akan dinilai. Menu Penilaian merupakan menu untuk melakukan proses penilaian menggunakan metode TOPSIS. Hasil dari penilaian ini adalah nilai alternatif/lokasi lahan rumput laut. Menu Hasil Penilaian menampilkan informasi tentang nilai masing-masing lokasi tambak rumput laut. Menu About digunakan untuk memberikan informasi tentang pembuat sistem

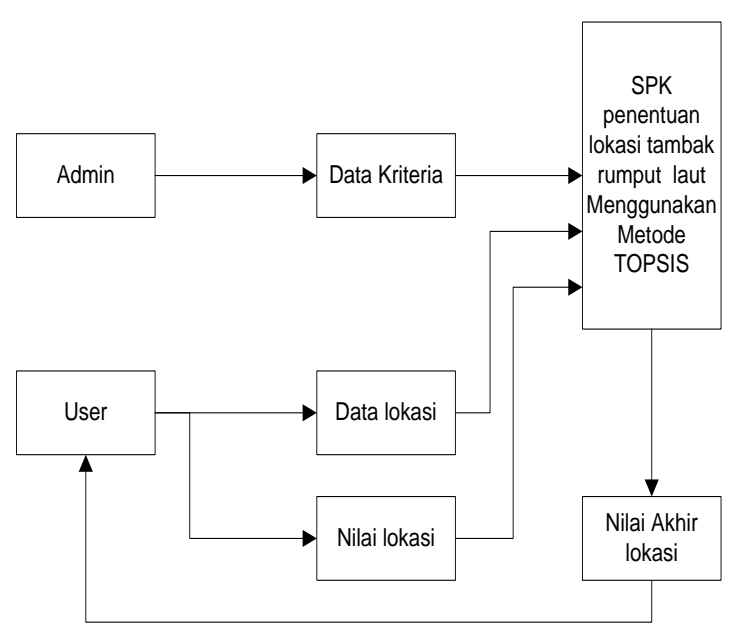

Gambar 2. Diagram Alir Sistem

\section{HASIL PENELITIAN}

4.1. Implementasi Sistem

Ketika sistem dijalankan, sistem akan menampilkan menu utama seperti yang ditunjukkan pada Gambar 3. dibawah ini.

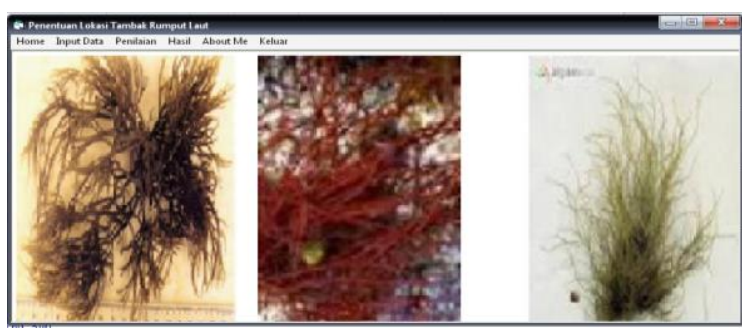

.Gambar 3. Menu Utama

Menu ini akan menampilkan informasi tentang latar belakang perlunya melakukanan analisa penentuan lokasi budidaya rumput laut. Keberhasilan budidaya rumput laut ditentukan oleh kondisi lokasi rumput laut .Keberhasilan budidaya rumput laut dengan pemilihan lokasi yang tepat merupakan salah satu faktor penentu.

Gambaran tentang biofisik air laut yang diperlukan untuk budidaya rumput laut penting diketahui agar tidak timbul masalah yang dapat menghambat usaha itu sendiri dan mempengaruhi mutu hasil yang dikehendaki. Dari uraian di atas, maka perlu adanya suatu evaluasi terhadap pembangunan yang telah dicapai, khususnya usaha budidaya tambak rumput laut yang meliputi aspek kesesuaian lahan, pemanfaatan lahan dan aspek ekonomis. Salah satu metode yang dapat digunakan untuk memilih lokasi budidaya rumput laut yang tepat adalah dengan menggunakan metode TOPSIS (Technique for Order Preference by Similarity to Ideal Solution). TOPSIS merupakan metode perangkingan dimana alternatif dirangking berdasarkan bobot masing-masinga lternatif. 


\subsection{Input Data Kriteria}

Input kriteria penilian yang digunakan akan digunakan dama pemilhan lokasi lahan budidaya rumput laut diantaranya : (K1) daerah stabil, (K2) kedalaman air, (K3) suhu, (K4) cahaya, (K5) salinitas dan (K6) tanaman alga seperti pada Gambar 4.

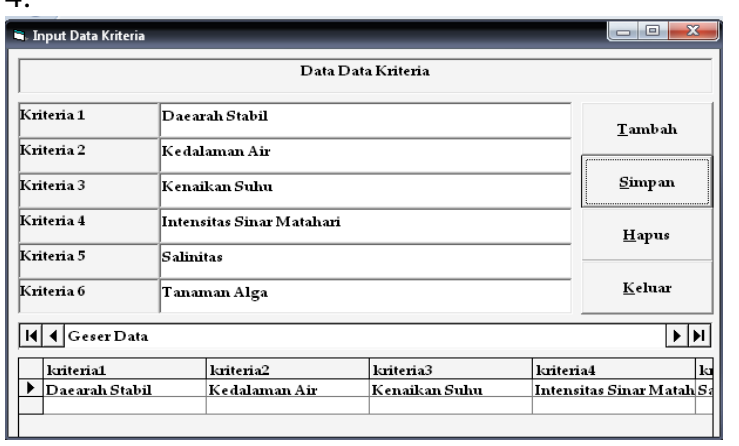

Gambar 4. Diagram Alir Sistem

Setelah memasukan kriteria maka dilakukan penyimapanan data pada tombol "Simpan". Sedangkan tombol "Tambah" digunakan untuk menambah data kriteria. Sedangkan Tombol "Hapus" digunakan untuk menghapus data kriteria. Tombol "Keluar" berguna untuk keluar dari menu kriteria.

\subsection{Input Data Lokasi}

Lokasi rumput laut yang akan dianalisa ada 5 (lima) lokasi. Semua lokasi berada di lokasi pesisir laut di sebelah selatan pulau Madura kabupaten Sampang.

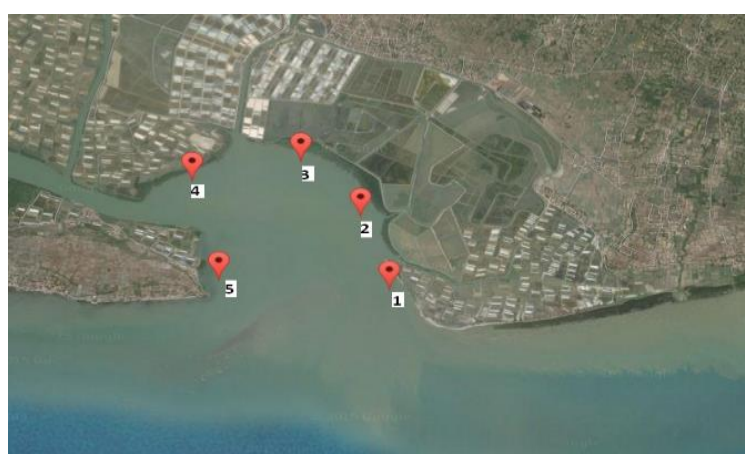

Gambar 5. Lokasi budidaya rumput laut

Gambar 5 menunjukkan bahwa lokasi budidaya rumput laut yang akan dinilai ada di 5 (lima) lokasi, dari lima lokasi tersebut akan dilakukan proses penilaian dan perangkingan berdasarkan kestabilan daerah, kedalaman air, kondisi suhu, kondisi cahaya, kondisi salinitas air dan kondisi sebaran tanaman alga.

Untuk memasukkan nama lokasi yang akan dinilai sebagaimana pada gamabar 6. Penilaian alternative di lima lokasi pesisir Kabupaten Sampang.

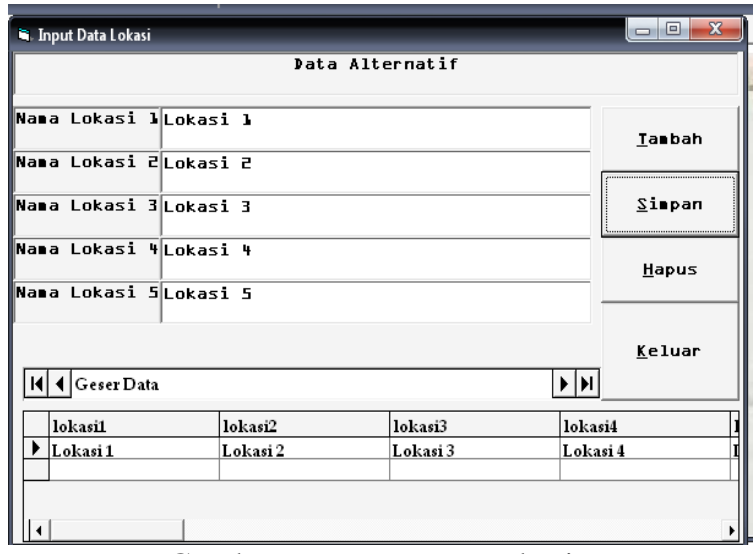

Gambar 6. Input Data Lokasi

\subsection{Input Nilai Kriteria}

Dalam memberikan nilai masing kriteria dapat dilakukan pada setiap kriteria yang ada diantaranya:

\section{a. Kriteria Daerah Stabil}

Untuk menghindari kerusakan fisik sarana budidaya maupun rumput laut dari pengaruh cuaca, dasar perairan yang paling baik untuk pertumbuhan Eucheumacottonii adalah yang stabil terdiri dari patahan karang mati dan pasir kasar serta bebas dari lumpur, dengan gerakan air (arus) yang cukup 20$40 \mathrm{~cm} /$ detik. Lokasi $1=20$, Lokasi $2=20$, Lokasi $3=$ 25, Lokasi $4=30$, dan Lokasi $5=25$.

\section{b. Kriteria Kedalaman Air}

Kedalaman air yang baik untuk pertumbuhan Eucheumacottonii adalah antara 2-15 m pada saat surut terendah untuk metode apung. Lokasi $1=3$, Lokasi $2=7$, Lokasi $3=6$, Lokasi $4=8$, dan Lokasi $5=9$.

\section{c. Kriteria Kenaikan Suhu}

Kenaikan temperatur yang tinggi mengakibatkan thallus rumput laut menja dipucat kekuning-kuningan yang menjadikan rumput laut tidak dapat tumbuh dengan baik. Oleh karena itu suhu perairan yang baik untuk budidaya rumput laut adalah $20-28^{\circ} \mathrm{C}$ dengan fluktua siharian maksimum $4^{\circ} \mathrm{C}$. Lokasi $1=3$, Lokasi $2=1$, Lokasi $3=2$, Lokasi $4=2$ dan Lokasi $5=1$.

\section{d. Kriteria Intensitas Sinar Matahari}

Tingkat kecerahan yang tinggi di perlukan dalam budidaya rumput laut.. Intensitas sinar yang diterima secara sempurna oleh thallus merupakan faktor utama dalam proses fotosintesis. Lokasi $1=5$, Lokasi $2=4$, Lokasi $3=2$, Lokasi $4=3$ dan Lokasi $5=3$.

\section{e. Kriteria Salinitas}

Rumput laut tumbuh pada salinitas yang tinggi.Penurunan salinitas akibat air tawar yang masukakan menyebabkan pertumbuhan rumput laut menjadi tidak normal. Salinitas yang dianjurkan untuk budidaya rumput laut sebaiknya jauh dari mulut muara sungai.Salinitas yang dianjurkan untuk budidaya rumput laut Eucheumacottonii adalah 28-35 ppt. Lokasi $1=29$, Lokasi $2=28$, Lokasi $3=29$, Lokasi $4=30$ dan Lokasi $5=28$. 


\section{f. Kriteria Tanaman Alga}

Sebaiknya untuk perairan budidaya Eucheuma dipilih perairan yang secara alami ditumbuhi oleh komonitas dari berbagai makro algae seperti Ulve, Caulerpa, Padina, dan lain-lain. Lokasi 1= 6, Lokasi $2=9$, Lokasi 3= 8, Lokasi $4=7$ dan Lokasi 5=7.

\subsection{Menghitung Matrik Ternormalisasi.}

Setelah semua nilai dimasukkan, selanjutnya menghitung nilai matrik ternormalisasi

\section{a. Kriteria Daerah Stabil}

Matrik ternormalisasi diperoleh dari membagi nilai dengan akar penjumlahan kuadrat nilai daerah stabil.

Lokasi $1=\frac{20}{\sqrt{20^{2}+20^{2}+25^{2}+30^{2}+25^{2}}}=0.368229847$
Lokasi $2=\frac{20}{\sqrt{20^{2}+20^{2}+25^{2}+30^{2}+25^{2}}}=0.368229847$
Lokasi $3=\frac{25}{\sqrt{20^{2}+20^{2}+25^{2}+30^{2}+25^{2}}}=0.460287309$
Lokasi $4=\frac{30}{\sqrt{20^{2}+20^{2}+25^{2}+30^{2}+25^{2}}}=0.552344771$
Lokasi $5=\frac{25}{\sqrt{20^{2}+20^{2}+25^{2}+30^{2}+25^{2}}}=0.460287309$

\section{b. Kriteria Kedalaman Air}

Matrik ternormalisasi diperoleh dari pembagian nilai dengan akar penjumlahan kuadrat nilai kedalaman air.

Lokasi $1=\frac{3}{\sqrt{3^{2}+7^{2}+6^{2}+8^{2}+9^{2}}}=0.194053868$
Lokasi $2=\frac{7}{\sqrt{3^{2}+7^{2}+6^{2}+8^{2}+9^{2}}}=0.452792359$
Lokasi $3=\frac{6}{\sqrt{3^{2}+7^{2}+6^{2}+8^{2}+9^{2}}}=0.388107736$
Lokasi $4=\frac{8}{\sqrt{3^{2}+7^{2}+6^{2}+8^{2}+9^{2}}}=0.517476982$
Lokasi $5=\frac{9}{\sqrt{3^{2}+7^{2}+6^{2}+8^{2}+9^{2}}}=0.582161605$

c. Kriteria Kenaikan Suhu

Matrik ternormalisasi diperoleh dari membagi nilai dengan akar penjumlahan kuadrat nilai kenaikan suhu.

$$
\begin{aligned}
& \text { Lokasi } 1=\frac{3}{\sqrt{3^{2}+1.5^{2}+2^{2}+2^{2}+1^{2}}}=0.666666667 \\
& \text { Lokasi } 2=\frac{1.5}{\sqrt{3^{2}+1.5^{2}+2^{2}+2^{2}+1^{2}}}=0.333333333 \\
& \text { Lokasi } 3=\frac{2}{\sqrt{3^{2}+1.5^{2}+2^{2}+2^{2}+1^{2}}}=0.444444444 \\
& \text { Lokasi } 4=\frac{2}{\sqrt{3^{2}+1.5^{2}+2^{2}+2^{2}+1^{2}}}=0.444444444 \\
& \text { Lokasi } 5=\frac{1}{\sqrt{3^{2}+1.5^{2}+2^{2}+2^{2}+1^{2}}}=0.222222222
\end{aligned}
$$

\section{d. Kriteria Intensitas Sinar Matahari}

Matrik ternormalisasi diperoleh dari membagi nilai dengan akar penjumlahan kuadrat nilai intensitas sinar matahari.

$$
\begin{aligned}
& \text { Lokasi } 1=\frac{5}{\sqrt{5^{2}+7^{2}+7^{2}+8^{2}+6^{2}}}=0.334824765 \\
& \text { Lokasi } 2=\frac{7}{\sqrt{5^{2}+7^{2}+7^{2}+8^{2}+6^{2}}}=0.468754671 \\
& \text { Lokasi } 3=\frac{7}{\sqrt{5^{2}+7^{2}+7^{2}+8^{2}+6^{2}}}=0.468754671 \\
& \text { Lokasi } 4=\frac{8}{\sqrt{5^{2}+7^{2}+7^{2}+8^{2}+6^{2}}}=0.535719624 \\
& \text { Lokasi } 5=\frac{6}{\sqrt{5^{2}+7^{2}+7^{2}+8^{2}+6^{2}}}=0.401789718
\end{aligned}
$$

\section{e. KriteriaSalinitas}

Matrik ternormalisasi diperoleh dari membagi nilai dengan akar penjumlahan kuadrat nilai intensitas salinitas.

Lokasi $1=\frac{29}{\sqrt{29^{2}+28^{2}+29^{2}+30^{2}+28^{2}}}=0.450167305$

Lokasi $2=\frac{28}{\sqrt{29^{2}+28^{2}+29^{2}+30^{2}+28^{2}}}=0.434644294$

Lokasi $3=\frac{29}{\sqrt{29^{2}+28^{2}+29^{2}+30^{2}+28^{2}}}=0.450167305$

Lokasi $4=\frac{30}{\sqrt{29^{2}+28^{2}+29^{2}+30^{2}+28^{2}}}=0.465690315$

Lokasi $5=\frac{28}{\sqrt{29^{2}+28^{2}+29^{2}+30^{2}+28^{2}}}=0.434644294$

\section{f. Kriteria Tanaman Alga}

Matrik ternormalisasi diperoleh dari membagi nilai dengan akar penjumlahan kuadrat nilai tanaman Alga.

Lokasi $1=\frac{6}{\sqrt{6^{2}+9^{2}+8^{2}+7^{2}+7^{2}}}=0.359210604$

Lokasi $2=\frac{9}{\sqrt{6^{2}+9^{2}+8^{2}+7^{2}+7^{2}}}=0.538815906$

Lokasi $3=\frac{8}{\sqrt{6^{2}+9^{2}+8^{2}+7^{2}+7^{2}}}=0.478947472$

Lokasi $4=\frac{7}{\sqrt{6^{2}+9^{2}+8^{2}+7^{2}+7^{2}}}=0.419079038$

Lokasi $5=\frac{7}{\sqrt{6^{2}+9^{2}+8^{2}+7^{2}+7^{2}}}=0.419079038$

\subsection{Matrik Ternormalisasi Terbobot}

Matrik ini diperoleh dengan cara mengalikan nilai dengan matrik ternormalisasi. Hasilnya ditunjukkan pada table berikut.

Tabel 1. Matrik ternormalisasi

\begin{tabular}{cl}
\hline Kode & Nama Kriteria \\
\hline K1 & Daerah Stabil \\
K2 & Kedalaman Air \\
K3 & Kenaikan Suhu \\
K4 & Intensitas Matahari \\
K5 & Salinitas \\
K6 & Tanaman Alga \\
\hline
\end{tabular}

\begin{tabular}{rrrrrrr}
\hline & \multicolumn{1}{c}{ K1 } & \multicolumn{1}{c}{ K2 } & \multicolumn{1}{c}{ K3 } & K4 & K5 & K6 \\
\hline Lokasi 1 & 7,36 & 0,58 & 2,00 & 1,67 & 13,05 & 2,15 \\
Lokasi 2 & 7,36 & 3,16 & 0,50 & 3,28 & 12,17 & 4,84 \\
Lokasi 3 & 11,50 & 2,32 & 0,88 & 3,28 & 13,05 & 3,83 \\
Lokasi 4 & 16,57 & 4,13 & 0,88 & 4,28 & 13,97 & 2,93 \\
Lokasi 5 & 11,50 & 5,23 & 0,22 & 2,41 & 12,17 & 2,93 \\
\hline
\end{tabular}

\subsection{Menghitung Nilai Mak dan Min}

Nilai maksimum adalah nilai paling tinggi untuk tiap kriteria.Nilai minimum adalah nilai paling rendah untuk tiap kriteria.

$\begin{array}{ll}\mathrm{y} 1+ & 16.57034 \\ \mathrm{y} 2+ & 5.239454 \\ \mathrm{y} 3+ & 2 \\ \mathrm{y} 4+ & 4.285757 \\ \mathrm{y} 5+ & 13.97071 \\ \mathrm{y} 6+ & 4.849343 \\ \mathrm{y} 1- & 7.364597 \\ \mathrm{y} 2- & 0.582162\end{array}$




$\begin{array}{ll}\text { y3 - } & 0.222222 \\ \text { y4 - } & 1.674124 \\ \text { y5 - } & 12.17004 \\ \text { y6 - } & 2.155264\end{array}$

4.2. Menghitung Nilai Jarak (D)

Nilai D positif nilai total didapat dengan menggunakan rumus.

$$
\begin{aligned}
& V_{1}=\frac{D_{1}^{-}}{D_{1}^{+}+D_{1}^{-}} \\
& V_{1}=\frac{1.98}{11.016+1.98}=0.5243 \\
& V_{2}=\frac{D_{2}^{-}}{D_{2}^{+}+D_{2}^{-}} \\
& V_{2}=\frac{4.07}{9.77+4.07}=0.4652 \\
& V_{3}=\frac{D_{3}^{-}}{D_{3}^{+}+D_{3}^{-}} \\
& V_{3}=\frac{5.18}{6.18+5.18}=0.5449 \\
& V_{4}=\frac{D_{4}^{-}}{D_{4}^{+}+D_{4}^{-}} \\
& V_{4}=\frac{10.42}{2.47+10.42}=0.5814 \\
& V_{5}=\frac{D_{5}^{-}}{D_{5}^{+}+D_{5}{ }^{-}} \\
& V_{5}=\frac{6.32}{6.26+6.32}=0.5803
\end{aligned}
$$

Berdasarkan analisa hasil pendekatan metode TOPSIS diperoleh sebagai berikut:

- Lokasi 1 memiliki nilai jarak 0.195 atau setara dengan $19.5 \%$.

- Lokasi 2 memiliki nilai jarak 0.173 atau setara dengan $17.3 \%$.

- Lokasi 3 memiliki nilai jarak 0.202 atau setara dengan $20.2 \%$.

- Lokasi 4 memiliki nilai jarak 0,216 atau setara dengan $21.6 \%$.

- Lokasi 5 memiliki nilai jarak 0.215 atau setara dengan $21.5 \%$.

Artinya potensi budidaya rumput laut dibeberapa lokasi di Kabupaten Sampang memiliki rentang kualitas yang sama sesuai dengan kriteria yang ada, yaitu: stabilitas daerah, kedalaman air, kenaikan suhu, intensitas matahari, salinitas air dan tanaman alga yang tersebar.

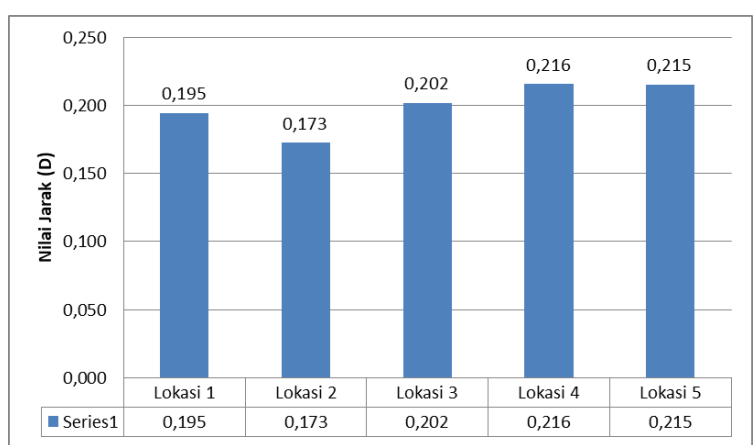

Gambar 7. Nilai jarak positif masing-masing lokasi

Gambar 7 menunjukkan bahwa prioritas lokasi yang direkomendasikan adalah lokasi 4, 5 dan 3, yaitu lokasi yang memiliki kondisi laut yang masih bagus dan cenderung pantainya memiliki kedalaman yang cukup, stabilitas air, suhu dan salitas baik.

Untuk lokasi 1 dan 2 memiliki nilai jarak yang jauh, sehingga potensi budidaya rumput laut diwilayah tersebut akan cenderung kurang potensial karena memiliki kondisi alam, cuaca dan arus yang kurang baik, hal ini disebabkan karena wilayah tersebut berada pada lokasi yang padat penduduk. Wilayah tersebut harus dilakukan peremajaan lingkungan dan meningkatkan kesadaran masyarakat untuk menjaga lingkunganya khususnya diwilayah pesisir.

Penelitian ini telah menjawab permasalahan penelitian yaitu telah merekomendasikan beberapa lokasi yang sangat potensi dan lokasi yang memiliki potensi rendah.

\section{KESIMPULAN}

Adapun kesimpulan yang dapat diperoleh dari hasil penelitian ini adalah:

1. Metode TOPSIS telah mampu membantu pengambil keputusan untuk menyelesaikan permasalahan yang kompleks.

2. Kriteria yang digunakan untuk menilai lokasi terbaik menggunakan 6 (enam) alternative.

3. Prioritas wilayah yang direkomendasikan oleh metode TOPSIS adalah lokasi 3,4,5 dengan nilai prioritas diatas $20 \%$, yaitu wilayah camplong dan sampan.

4. Lokasi yang tidak direkomendasikan adalah lokasi 1 dan 2 dengan nilai dibawah $20 \%$, yaitu wilayah sreseh dan pengarengan.

\section{DAFTAR PUSTAKA}

Heru Lumaksono, H. (2017). Sistem Pendukung Keputusan untuk Menentukan Alat Tangkap yang Sesuai bagi Nelayan di Madura. In Seminar MASTER 2017 PPNS (Vol. 1509, pp. 1-6).

Hozairi, Y. K. (2018). Decision Support System Determination of Main Work Unit in WPP711 using Fuzzy TOPSIS. Knowledge Engineering and Data Science, 1(1), 8-19.

Kutlu, A. C. (2012). Fuzzy failure modes and effects analysis by using fuzzy TOPSIS-based fuzzy AHP. Expert Systems with Applications, 39, 
61-67.

https://doi.org/10.1016/j.eswa.2011.06.044

Muhammad Z.Zain, F. B. (2012). Analisa

Kesesuaian Lahan dan Strategi Pengembangan

Budidaya Cracilaria sp di Area Tambak di Kecamatan Ulujami Kabupaten Pemalang. Perikanan, XIV(2), 71-79.

Murnawan, \& Siddiq, A. F. (2012). Sistem Pendukung Keputusan Menggunakan Metode Technique for Order by Similarity to Ideal Solution (TOPSIS). Jurnal Sistem Informasi, 4(1), 398-412.

Paena, M. (2013). Analisis kesesuaian lahan budidaya rumput laut di kabupaten minahasa utara provinsi sulawesi utara. Akuakultur, 8(3), 985-995.

Shukla, R. K., Garg, D., \& Agarwal, A. (2014). An integrated approach of Fuzzy AHP and Fuzzy TOPSIS in modeling supply chain coordination. Production \& Manufacturing Research, 2(1), 415-438. https://doi.org/10.1080/21693277.2014.91988 6

Siswanto, A. D., \& Nugraha, W. A. (2016). Permasalahan Dan Potensi Pesisir Di Kabupaten Sampang. Jurnal Kelautan: Indonesian Journal of Marine Science and Technology, 9(1), 12. https://doi.org/10.21107/jk.v9i1.1034 